\title{
COMPLICATIONS OF TRANSURETHRAL PROSTATIC SURGERY
}

\author{
John Desmond, M.B.B.S., F.R.C.P.(c) ${ }^{\circ}$
}

THERE ARE probably very few operations in which a patient can be subjected to such a large number of unphysiological insults at one time as during a transurethral prostatectomy. The experienced resectionist and the well-trained anaesthetist have little trouble in recognizing and managing the problems if and when they occur, but for the occasional resectionist and the resident in training the early recognition of these problems is imperative. In reviewing the literature over the past twenty years, there can be no question that a great deal of research has been carried out in this area, and several interesting review articles have been written. That by Marx and Orkin ${ }^{1}$ is of particular interest. Since its publication, much of the work has been redone in this centre and, while confirming the work done by other investigators, we have added some of our own ideas and findings. As a result, it has now become possible to describe with some accuracy the physiopathological state often seen when overhydration occurs in these patients (Fig. 1).

TABLE I

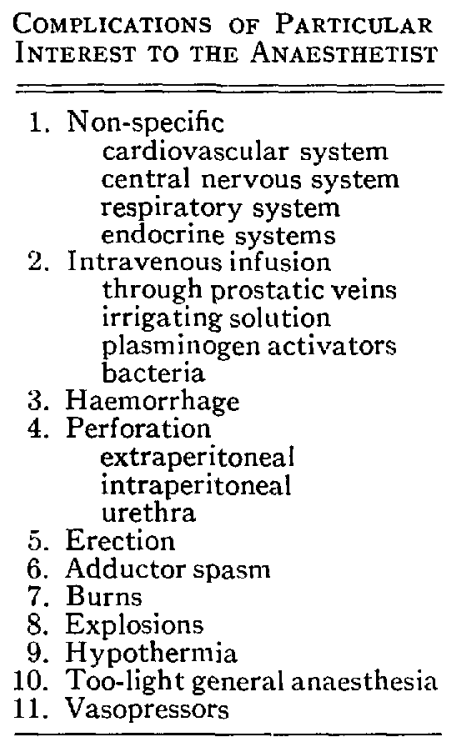

By definition a transurethral resection of the prostate is one in which the surgeon resects the gland down to the capsule. Any procedure short of this is likely to make another operation necessary at a later date since it is a prostatic adenoma that is being resected. The fact that a large quantity of sloughing

-The Department of Anaesthesia, University of Toronto, and the Toronto General Hospital. 
adenomatous tissue is likely to be left in an incomplete resection further complicates the care of the patient in the postoperative period. Bleeding and inability to void properly are commonly seen in such cases. In performing such a resection the surgeon will frequently cut into a large number of venous sinuses during the course of the operation and many of the problems which will be discussed in this paper relate to this fact.

A variety of irrigating solutions are used. The ideal solution would of necessity have to be optically satisfactory, iso-osmolar and non-haemolytic. It must also be weakly ionizable in order to inhibit the dispersion of high radio-frequency current (voltage 1000 amp. 1.5) which might otherwise injure both the surgeon and the patient. Finally, it must be inexpensive. While the surgeon is resecting the gland, the irrigating fluid is normally permitted to flow into the bladder, increasing the intravesicular pressure and, as a result, absorption of fluid into the cut venous sinuses may occur.

Though water is still widely used for irrigating the bladder, its use must be condemned. Five hundred $\mathrm{ml}$ of water entering the vascular compartment will rapidly destroy $1_{2}^{\prime-1} \mathrm{gm} \mathrm{Hb}$ per cent.,3 Two other commonly used solutions will be mentioned and discussed. These are glycine 1.2 per cent and Cytal (Table II). 2,6

TABLE II

\begin{tabular}{|c|c|c|}
\hline Glycine $(1.2 \%)$ & $\begin{array}{l}\text { simple amino acid exists } \\
\text { in the body, plasma level } \\
1.3 \text { to } 1.7 \mathrm{mg} \%\end{array}$ & $\begin{array}{l}\text { cheap-ideal for } \\
\text { large institutions }\end{array}$ \\
\hline Cytal & $\begin{array}{l}\text { sorbital } 2.7 \mathrm{gm} \text { (isomer) } \\
\text { of mannitol } \\
\text { mannitol } 0.54 \mathrm{gm}\end{array}$ & $\left.\begin{array}{l}18 \mathrm{~m} .0 \mathrm{sm} / \mathrm{kg} / \text { sodium free } \\
\text { osmolality } 285\end{array}\right\} \begin{array}{c}\text { expensive-ideal for } \\
\text { small institutions }\end{array}$ \\
\hline
\end{tabular}

Glycine, a simple aliphatic amino acid, has carboxylic and amino groups attached to the same carbon atom. ${ }^{4}$<smiles>[R]C(N)C(=O)O</smiles>

It occurs normally in the body; the plasma levels are $1.3-1.7 \mathrm{mg}$ per cent. The distribution of glycine in the plasma and liver appear to be equal, with less in the kidney. The heart contains little and the muscle very little because of the limited permeability of the muscle cells. Glycine is normally broken down along four pathways. One of these, oxidative deamination, leads to the formation of glyoxylic acid and a formate fragment (ammonia). The formation of ammonia and its release into the circulation has been questioned by Hoyt. He states that glycine is a potentially toxic substance ${ }^{5}$ and questions its use for this type of surgery. Animal experiments showed that exceedingly high levels of glycine must be reached in the plasma before toxic symptoms occurred $(0.4-1 \mathrm{gm} / \mathrm{kg}$ ). The controls carried out on human volunteers were poor and in this author's opinion of no value. In our own experience, glycine 1.2 per cent (osmolality 220) has 
provided an ideal irrigating solution. In over 400 cases, which have been closely followed by the author and in which large amounts of irrigant were absorbed with marked falls in plasma sodium levels, we saw none of the toxic signs and symptoms referred to by other investigators. In a large institution where 140 litres of sterile irrigant solution are prepared every day, it is essential that such a solution should be reasonably inexpensive.

Cytal is the trade name for a non-haemolytic irrigating solution, the principle constituents of which are two hexitols, sorbital $(2.7 \mathrm{gm})$ and mannitol $(0.54 \mathrm{gm})$ per $100 \mathrm{cc}$. It is isomolar, and is cleared from the plasma rapidly. For a small institution this would be the ideal irrigating solution. ${ }^{6}$

\section{Age Group and Cardiovascular Status}

It must never be forgotten that this operation is usually performed on an aged population. In our series 60 per cent of the patients were between the ages of 70 and 90. Cardiac disease was present in 67 per cent of these patients (Tables III and IV). Exposing such patients to vascular overloading and hyponatraemia is not without risk, and the watchful eye of those concerned with the procedure must always be focussed on the recognition and prevention of these complications.

TABLE III

Age Groups of Patients Having

Transurethral Prostatic Surgery*

\begin{tabular}{cc}
\hline Age & Number of patients \\
\hline $50-60$ & 6 \\
$60-70$ & 19 \\
$70-80$ & 23 \\
$80-90$ & 20 \\
\hline${ }^{*} 60 \%$ of patients over 70 years of age
\end{tabular}

$25 \%$ of patients over 80 years of age.

TABLE IV

Cardiac Status of Patients Having Transurethral. Prostatic Surgery*

\begin{tabular}{lr}
\hline Number of consecutive patients reviewed & 60 \\
Previous history and electrocardiographic evidence & \\
of myocardial infarction & 22 \\
Complete heart block - pacemaker & 2 \\
Bundle branch block & 6 \\
Myocardial ischemia, angina, hypertension, & 10 \\
ventricular extra systoles & 40 \\
Tota! &
\end{tabular}

*Sixty-seven per cent of patients had evidence of myocardial disease.

\section{Vascular Overloading with Irrigating Fluid}

Taylor et al. ${ }^{7}$ in 1958 showed that out of 25 patients on whom he had operated, 8 had absorbed more than $1100 \mathrm{gm}$ of irrigating fluid. Five of these absorbed 
over $2250 \mathrm{gm}$. Hagstrom, ${ }^{8}$ plotting weight gains (acquisition of an equal quantity of irrigant solution) against resection time, found in 1955 that there were $10-30 \mathrm{cc}$ of fluid absorbed per minute of operating time. A year later Maluf et al. ${ }^{9}$ reported on 15 patients, stating that 14 of them showed $100-4500$ gm weight gain - averaging $1990 \mathrm{gm}$. Two of his patients gained $9 \mathrm{lbs}$. For vascular hyperhydration to occur, it is necessary first that the surgeon cut through a venous sinus and secondly that the pressure of the irrigating fluid in the bladder be higher than the prostatic venous pressure. It has long been known that if a surgeon permits the intravesicular pressure to remain high for a long period of time, the opening of only one large sinus can cause a fairly large quantity of fluid to be absorbed.

\section{EFFects of INTRAVASCULAR INfUSION OF THE IRRIGATING SOLUTION}

What happens to the fluid that enters the vascular compartment depends in large part on the capability of the left ventricle to handle it and to move it into the interstitial compartment, and also on whether a hypo-osmolar or an isoosmolar irrigating solution has been used (Table V).

TABLE V

Factors Influencing the Amount and Rate of Absorption OF JRRIGATING FLUID

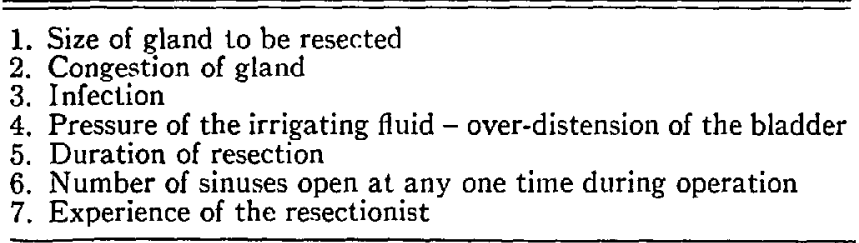

The anaesthetist plays an important role in the recognition of irrigant absorption and vascular overloading. If the surgeon is prewarned, he will bring the operation to an end as soon as possible, and it is the alert anaesthetist who warns him of changes in the patient's condition which if allowed to continue would prove disastrous.

Figure 1 describes what we believe to be the physiopathological changes that occur with vascular hyperhydration. The diagramatic representation of the physiopathology of glycine infusion shows what happens when there is good left ventricular function and slow absorption of the irrigating fluid, and also what happens when there is poor left ventricular function and the absorption of fluid is rapid. In the former case, very few changes are likely since the efficient left ventricle can move most of this fluid into the interstitial compartment. Slight dilutional hyponatraemia may occur as $10-15 \mathrm{mEq}$ of sodium move out with each $100 \mathrm{cc}$ of fluid into this compartment. There is also an absolute loss of sodium (60-70 $\mathrm{mEq}$ ) from the resection site. The serum osmolality remains normal even though glycine 1.2 per cent is slightly hypo-osmolar. We believe that the distribution of glycine is occurring much more slowly in these cases, and as the fluid is moved into the interstitial compartment the concentration of glycine 


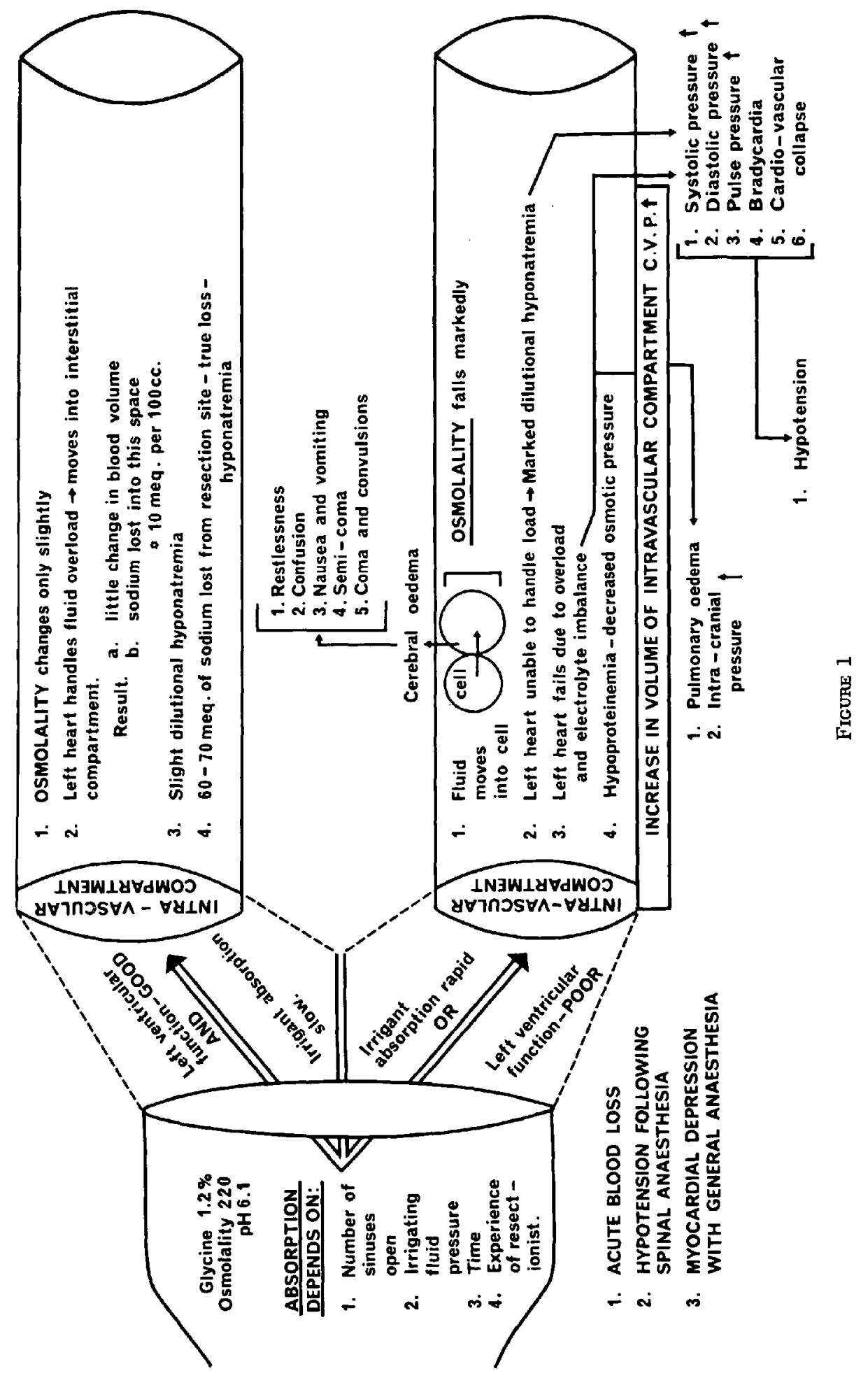


TABLE VI

\begin{tabular}{ccl}
\hline No. of cases & $\begin{array}{c}\text { Fall in sodium } \\
(\mathrm{mEq} / \mathrm{L})\end{array}$ & \multicolumn{1}{c}{ Osmolality } \\
\hline 1 & 54 & no change \\
2 & 40 & no change \\
2 & 34 & no change \\
1 (pulmonary oedema) & 30 & fell to 256 \\
1 (pulmonary oedema) & 27 & fell to 260 \\
1 & 26 & no change \\
5 & 16 & no change \\
1 & 14 & no change \\
2 & 13 & no change \\
2 & 12 & no change \\
2 & 10 & no change \\
5 & 9 & no change \\
3 & 8 & no change \\
3 & 7 & no change \\
2 & 6 & no change \\
2 & 5 & no change \\
3 & no significant changes \\
34 & no significant changes & 2 patients with changes in os- \\
Total 72 & molality - both developed \\
& changes in sodium & cerebral and pulmonary \\
& & oedema \\
\hline
\end{tabular}

in the intravascular compartment is increased. We confirmed this analysis in a study in which we measured the sodium osmolality and plasma electrolytes in 72 randomly selected patients. The results of this study are shown in Table VI. Even though there were marked falls in the plasma sodium in 19 per cent of cases, in only two cases did the serum osmolality change. The reason for the changes in these two cases will be explained when the effects of too-rapid infusion of irrigating fluid in the patient with poor left ventricular function are described. In such cases the irrigant fluid remains in the vascular compartment and changes take place in intravascular pressure, osmolality, plasma sodium, and plasma proteins. In addition the left ventricle begins to fail and pulmonary oedema develops. The changes in osmolality due to the marked dilutional hyponatraemia and hypo-osmolar glycine retention lead to cerebral oedema. Eventually hypotension and renal shut-down occur.

In treating these patients it therefore becomes imperative at all times to know the values of the serum osmolality and plasma electrolytes. In the patient with a normal serum osmolality and low plasma sodium we have found that no treatment is usually necessary. ${ }^{10}$ In the patient who experiences changes in both serum osmolality and plasma sodium, heart failure is likely, and active measures must be taken to prevent it. Diuretics and 5 per cent saline $(855 \mathrm{mEq} / \mathrm{L})$ can be used in these cases. We suggest that repeated measurements of plasma electrolytes and serum osmolality be instituted throughout the period when the patient's condition remains critical. It would be foolish to think that a definite trend develops in each case. Factors such as bleeding, anaesthesia which is too light or too deep, myocardial depression, hypovolaemia, hypotension associated with inadvertently high spinal anaesthesia, and improper use of vasopressor 
drugs will alter the picture which finally evolves and each patient must be managed on an individual basis, taking into account all the factors mentioned above. There is, consequently, no classic triad which we can depend on to guide us. ${ }^{1}$ It has been our experience, especially in a training programme, that measurements of blood pressure, pulse, central venous pressure, blood loss, serum osmolality, plasma electrolytes and haematrocrits are all necessary and important if proper evaluations are to be made with regard to the clinical condition of the patient at any particular time.

\section{Plasminogen Activation}

The activation of plasminogen by a local tissue activator from prostate or pancreatic tissue can occur during surgery.

Lombardo ${ }^{11}$ reported that 1.5 per cent of his cases showed evidence of fibrinolysis. The problem is significant and the mechanism of activators should therefore be mentioned.

Plasminogen (profibrinolysin) is the precursor of the active enzyme plasmin which is found in the globulin portion of the blood. It is normally antagonized by antiplasmin found in the albumen fraction. When plasminogen is activated by the proteolytic enzyme from the prostatic gland, plasmin is formed and this digests the fibrinogen. Fetter and Tocantus ${ }^{12}$ reported in 1961 on the use of epsilon aminocaproic acid (EACA), a competitive plasminogen inhibitor, during transurethral resection of the prostate. According to the resectionist, blood loss was very low when $4 \mathrm{gm} / 250 \mathrm{cc}$ were used during the first hour of resection and a continuous drip containing $57 \mathrm{gm}$ in 4 litres was used for the next 48 hours at $1 \mathrm{gm} / \mathrm{hr}$.

We have used epsilon aminocaproic acid with good results in the recovery room on many occasions when the patient was bleeding profusely. Blood is first taken for coagulogram and then the surgeon gives the patient 4-5 gm. (16-20 cc) by intravenous infusion over the period of one hour.

\section{BACTERAEMia}

Bacteria from an infected urinary tract readily enter the circulation during the resection. Prophylactic coverage of all transurethral resections of the prostate with intravenous gantrisin and broad spectrum antibiotics has reduced the dangers of bacteraemia to a large extent. In our own study, we did blood cultures on all patients who shivered in the operating room or recovery room and in no case did we culture any organisms. In spite of this, 3 per cent of our patients developed gram negative septicaemia in the 12-36 hour period. The recognition of this complication is therefore important and immediate treatment must be instituted because of the danger of vascular collapse in these patients. Probably a great many of the patients undergoing this operation get some degree of bacteraemia. Sterile technique is a vital part of the procedure. Bacterial cultures of the irrigating fluid must be done frequently. The irrigating fluid, particularly if it is stored in large tanks, must be sterilized daily and at no time must the sterile technique instituted by the surgeon in the operating room be broken. 
The diagnosis is usually made when the patient begins to experience chills and an increasing fever is noted. Arterial hypotension, bradycardia, and vascular collapse can follow very quickly, being more commonly seen with gram negative bacteraemia. E. coli-aerobacter aerogenes - pseudomonas and proteus - are cultured in approximately two thirds of all cases where there has been positive blood culture. Supportive therapy and massive doses of broad spectrum antibiotics are needed in all these cases.

Shivering occurring during the resection and early postoperative period is most likely due to halothane anaesthesia, cold blood transfusion reaction, cerebrovascular accident, or spinal anaesthesia.

\section{Haemorrhage}

Severe arterial and venous bleeding commonly occur with this operation. Common causes of haemorrhage are listed in Table VII. This complication has been dealt with in detail in a separate paper to which the reader is asked to refer. ${ }^{13}$

There is no question that when adequate attention is paid to the factors which influence bleeding, a great deal of haemorrhage can be prevented. In our series where blood loss was measured, during an eight month period we used one third the amount of blood used during the eight months prior to the commencement of the study. The introduction of the Fisher haemophotometer in the operating room where the survey was performed has changed things considerably. For three years, we have measured blood loss in all patients subjected to this operation and by avoiding over-transfusion in some cases and under-transfusion in others, we have reduced one of the major factors detrimental to the progress of the patient.

TABLE VII

Factors InfLUENCING HaEmorrhaGe

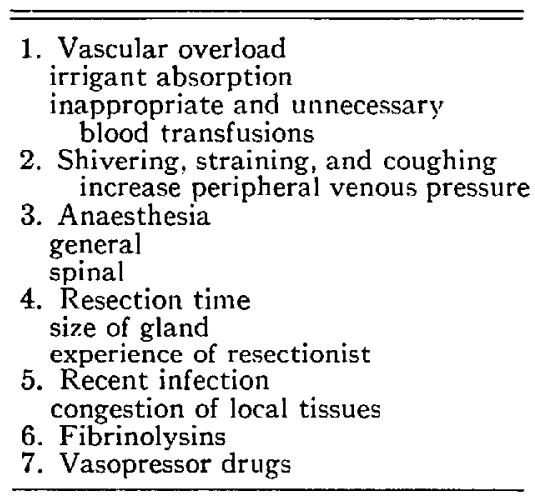

\section{Too-light General Anaesthesia}

At times one is forced into a very precarious position when giving these patients a general anaesthetic. Analgesia must be adequate and yet such analgesia often requires deepening of the anaesthesia to the point where the blood pres- 
sure falls to undesirably low levels. In a number of cases in which we measured the central venous pressure, in patients who were having $\mathrm{N}_{2} \mathrm{O}$ and halothane following a thiopentone induction, we found that at the instant when the first cut was made into the gland the pressure rose to $24-30 \mathrm{~cm} \mathrm{H}_{2} \mathrm{O}$. At the same time the patient's abdominal muscles became tense, the pattern of respiration changed, and before long the surgeon was complaining that the straining was disturbing his work. It became evident that this technique was providing unsatisfactory analgesia and, as a result, we now give the patient small increments of Innovar as well throughout the procedure. This has provided the necessary analgesia and has also helped to keep the patient quiet during the first hour in the recovery room. The importance of this latter condition cannot be stressed enough. To see a patient shivering and straining in the recovery room with severe muscle rigidity and blood pouring from his catheter is not very pleasant. This never occurs when the patient has had a spinal anaesthetic and need not occur if a properly administered general anaesthetic has been given. It is also recommended that the patient be kept asleep till the very last moment before he is gently transferred from the operating table to his bed. The patient should then be allowed to wake up quietly in the recovery room.

\section{Perforation of the Bladder}

Nesbitt et al. ${ }^{14}$ in 1966 described the characteristic signs and symptoms of perforation of the bladder as follows:

Intraperitoneal - shoulder-tip pain followed shortly by nausea and abdominal distension, in rapid sequence.

Extraperitoneal - same pattern, but more slowly, no shoulder tip pain.

Extravasation into periprostatic tissue - low suprapubic discomfort; suprapubic space may be visibly distended and firm; blood pressure rises; bradycardia; nausea and vomiting.

One would not expect to see many of the above signs and symptoms during general anaesthesia and because of this more care is necessary to prevent this occurring when the patient is asleep. Constantly feeling the patient's abdomen for rigidity is a practice which should be encouraged. A rigid abdomen can also occur with too-light anaesthesia. As has been shown, this is disturbing to the resectionist and should be avoided if bleeding is to be prevented. Often the surgeon realizes that he is losing irrigating fluid and that he may have perforated the bladder. If perforation has occurred the patient goes into extreme shock and immediate suprapubic drainage must be instituted.

\section{Inadvertently High Spinal Anaesthetic and the Danger of UsING VASOPRESSORS}

If, through some error in technique or positioning, the patient should get a level of spinal anaesthesia high enough to cause hypotension, then the operation should be delayed till another day. This is preferable to giving the patient a vasopressor to raise the pressure. The following case illustrates why this suggestion has been made. 
An elderly patient was given an inadvertently high spinal anaesthetic and his systolic blood pressure fell to $80 \mathrm{~mm} \mathrm{Hg}$. During the succeeding 30 minutes he received Vasoxyl $4 \mathrm{mg}$ iv on four occasions to maintain his blood pressure. After 30 minutes of resecting the patient became dyspnoeic, cyanosed, and confused. Eventually, his respiration became embarrassed and it was evident that he was in pulmonary oedema. Intubation and positive pressure ventilation were immediately instituted and through the combined efforts of the surgeon and anaesthetist the patient gradually recovered. His plasma sodium at the time of the catastrophe was $110 \mathrm{mEq} / \mathrm{L}$ (Fig. 2). What actually happened in this case was that the vasopressor had shut down the patient's arterioles and the irrigant fluid he was absorbing from the venous sinuses could not be moved out of the vascular compartment. As a result he very soon had left heart failure. There have been several such cases during the past four years and the use of vasopressors to raise the blood pressure at the expense of closing down the peripheral arterioles must be deplored.

The same reasoning would apply to vasopressors given during surgery, particularly if one suspects that vascular overload has occurred. The work of the failing left heart will be greatly increased and pulmonary oedema will occur soon after the vasopressor has been administered. To avoid the problem of hypotension in the patients who receive spinal anaesthesia we place them in a "reverse Trendelenberg" position during the injection of the anaesthetic solution.

\section{Burns}

Voltages of 1000 at $1-1.5$ amps ( $1000 \mathrm{~W}$ ) are used for cutting and cauterizing in this procedure. Not only is the patient subjected to the hazard of burns, but the surgeon can get a serious electric shock. To avoid both these hazards, proper maintenance and care of the electrosurgical unit are necessary. The ground plate, ground wires and wall-plug outlet must be checked frequently. The proper conductive plate jelly must always be used. If the jelly dries out during the operation, the contact between ground plate and patient ceases to conduct and the resistance to current flow begins to grow rapidly with resultant absorption of energy from the current. This heats the jelly and the resistance increases further with an increase in absorbed energy. In a short time the jelly in contact with the patient is so hot that a severe burn results. At the same time the surgeon observes that the electrosurgery is less efficient and requests an increase in the power setting. Before this is done, the ground plate, the adequacy of the conductive jelly, and the cord should be checked, since there may be a serious ground-lead fault present. One should make sure that the patient and table are adequately grounded before making any changes in the power setting of the unit. The electrosurgical unit is the surgeon's responsibility, but the patient is everyone's responsibility and so it is important to be aware of the dangers when a request for increase in the power setting is made. A gowned and gloved surgeon cannot check the ground plate-patient contact. An astute and helpful anaesthetist can do this for him. 


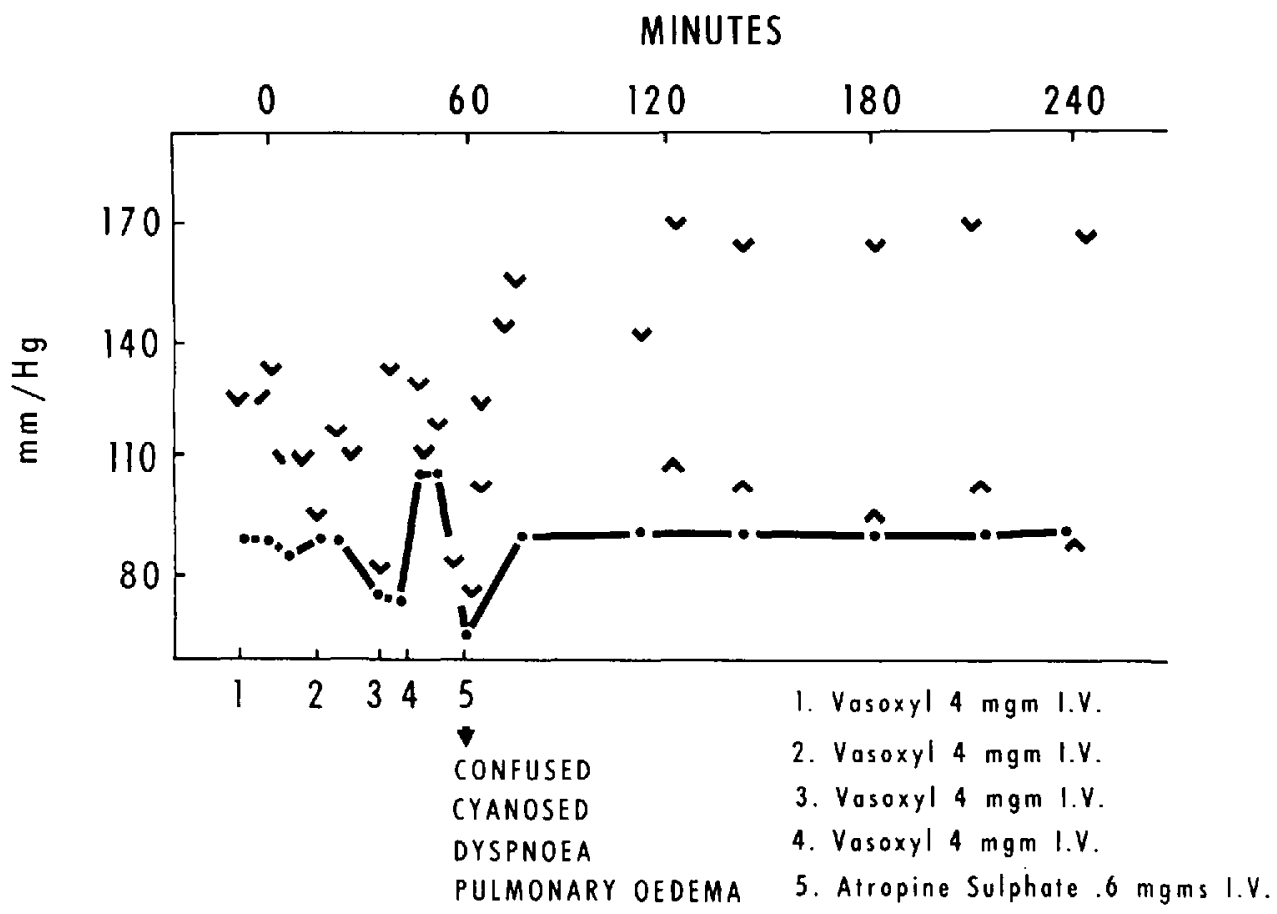

Figure 2

It should have become apparent by now that much of the morbidity and mortality associated with this type of surgery can be avoided with proper understanding and management. It is an operation in which the surgeon and the anaesthetist must be aware of and at all times alert to the dangers confronting the patient. Urologists admit that this is probably the most difficult operation to teach a resident in training and that it takes many years to acquire any degree of skill. The attitude that bleeding and vascular overloading are a surgical problem and that the anaesthetist has no concern with these matters is wrong. While the surgeon is performing this difficult procedure, the anaesthetist can do much to help him. Close observation of the patient's condition, checking the blood loss, and warning the surgeon when changes appear which might indicate vascular overloading are all part of the anaesthetist's responsibility. In our institution we have reduced the morbidity considerably and the mortality during the past three years from 1.5 to 0.4 per cent.

\section{SUMMARY}

The complications of transurethral prostatic resection have been discussed, with special reference to the role of the anaesthetist in this procedure. Hyperhydration, bleeding, perforation of the bladder, the abuse of vasopressors in both spinal and general anaesthesia have been discussed. The physiopathology of glycine absorption into the vascular compartment has been defined and tabulated 


\section{RÉSUMÉ}

On a étudié les complications de la résection prostatique trans-uréthrale en tenant compte du rôle que peut jouer l'anesthésiste dans cette opération. L'hyperhydratation, le saignement, la perforation de la vessie, l'abus des vaso presseurs au cours de l'anesthésie tant rachidienne que générale ont été discutés. La physiologie de l'absorption de la glycine dans le système vasculaire a été défnie et classifiée.

\section{REFERENCES}

1. Marx, Gertie F. \& Orkin, Lours R. Complications Associated with Transurethral Surgery. Anesthesiology. 23: 802 (1962).

2. Creevy, C. D. Haemolytic Reactions during Transurethral Prostatic Resection. J. Urol. 58: 125 (1947).

3. Creevy, C. D. Importance of Haemolysis during Transurethral Prostatic Resection. J. Urol, 59: 1217 (1948).

4. Nesbritr, T. E. The Use of Glycine in Transurethral Prostatic Surgery. J.A.M.A. 156: $1042(1954)$.

5. Hoyt, S. H. et al. Tr. West. Sec. Am. Urol. A. 24: 29 (1957).

6. Schulte, T. L.; Hammer, Howard J.; \& Reynolds, L. Clinical Use of Cytal in Urology. J. Urol. 71 : no. 5 (1954).

7. Taylor, R. O.; Maxson, E. S.; Carter, F. H.; Bethard, W. F.; \& Prentiss, R. J. Volumetric, Gravimetric and Radio Isotopic Determination of Fluid Transfer in Transurethral Prostatectomy. J. Urol. 79: 490 (1958).

8. Hacstrom, R. S.; Dennise, S. A.; Rowland, H. S.; Vinson, C.; \& Brunts, R. Studies on Fluid Absorption during Transurethral Prostatic Resection. J. Urol. 73: 852 (1955).

9. Malur, N. S.; Boren, J. S.; \& Brandes, Q. E. Absorption of Irrigating Solution and Associated Changes upon Transurethral Electro Resection of the Prostate. J. Urol. 75: 824 ( 1956).

10. Hastings, K. \& Wright, D. Severe Post Operative Hyponatremia without Symptoms of Water Intoxication. Surg., Gynec. \& Obst. 115: 553 (1962).

11. Lombardo, L. J. Studies in the Prevention of Fibrinolysis Occurring in Prostatic Surgery. J. Urol. 79: 507 (1968).

12. Fetrer, T. \& Tocantus, L. The Effect of Epsilon Aminocaproic Acid on Bleeding after Prostatectomy. J. Urol. 85: 970 (1961).

13. Desmond, J. \& Gordon, R. A. Bleeding during Transurethral Prostatic Surgery. Canad. Anaesth. Soc. J. 16: no. 3 (1969).

14. Nesertr, T. E.; CARter, D. W.; Tudor, J.; \& MCGlellan, R. Complications of Transurethral Prostatectomy and Their Management. South. Med. A. J. 59: 361 (1966). 